\title{
Myopia onset and role of peripheral refraction
}

This article was published in the following Dove Press journal:

Clinical Optometry

16 June 2017

Number of times this article has been viewed

\section{Maurilia Rotolo 1,2 \\ Giancarlo Montani² \\ Raul Martin ${ }^{1,3}$}

'Optometry Research Group, IOBA Eye Institute, School of Optometry, Universidad de Valladolid, Valladolid, Spain; ${ }^{2}$ Optics and Optometry, Corso di Ottica e Optometria, Universita del Salento, Lecce, Italy; ${ }^{3}$ Faculty of Health and Human Sciences, School of Health Professions, Plymouth University, Peninsula Allied Health Centre, Plymouth, UK
Correspondence: Raul Martin Optometry Research Group, IOBA Eye Institute, School of Optometry, Universidad de Valladolid, Paseo de Belén. 7 - Campus Miguel Delibes. 470II Valladolid, España Email raul@ioba.med.uva.es
Background: To determine the peripheral refraction characteristics related to 18-month changes in refraction in Caucasian (Mediterranean) children.

Methods: Non-cycloplegic peripheral refraction at $10^{\circ}$ intervals over the central $\pm 30^{\circ}$ of horizontal visual field over 18 months (baseline, 12 months, and 18 months of follow-up) was conducted in 50 healthy children who were 8 years old. Axial length (AL) was also recorded. Relative peripheral refraction (RPR) was calculated and eyes were divided into three study groups: non-myopic eyes, myopic eyes, and eyes that develop myopia.

Results: Myopic eyes showed hyperopic RPR and emetropic and hyperopic eyes showed myopic RPR. Univariate analysis of variance did not find any statistically significant effect of peripheral refraction $\left(F_{36}=0.13 ; P=1.00\right)$ and $\operatorname{RPR}\left(F_{36}=0.79 ; P=0.80\right)$ on myopia onset (eyes that developed myopia along the study). All the studied groups showed an increase of AL, without statistically significant differences between the studied groups $\left(F_{6}=0.09 ; P=0.99\right)$.

Conclusion: Hyperopic relative peripheral shift change in eyes that develop myopia has been found with differences in RPR between myopic (hyperopic RPR) and hyperopic or emmetropic eyes (with myopic RPR). The results suggest that RPR cannot predict development or progression of myopia in Caucasian (Mediterranean) children and the efficacy in slowing myopia progression obtained with treatments that manipulate the peripheral refraction is not just driven with RPR. Keywords: myopia, refractive errors, myopia onset, peripheral refraction, relative peripheral hyperopia

\section{Plain language summary}

Myopia (short sight) affects $25 \%-80 \%$ of people depending on demographic, race, and other factors. Recent research suggests that peripheral refraction plays a relevant role in myopia onset and progression, as other different hereditary and environmental factors such as genetics (myopic parents), short periods of outdoor activities, and others. There are small reports conducted in Caucasian children, so the results obtained in Asian population could be different from the results obtained in Caucasian population.

This study assesses the impact of peripheral refraction in a small sample of 50 healthy Caucasian children, measuring the peripheral refraction at $5^{\circ}$ intervals over the central $60^{\circ}$ of horizontal visual field along 18 months in order to provide better information to clinicians for prescribing different options to halt or slow myopia progression.

The results suggest that the efficacy in slowing myopia progression obtained with treatments that manipulate the peripheral refraction should be related with other factors different from peripheral refraction in Caucasian children. 


\section{Introduction}

The results of animal studies propose that peripheral refraction may play a significant role in eye's emmetropization process, in myopia development, and in its progression. ${ }^{1}$ Myopia onset could be related with different hereditary and environmental factors ${ }^{2}$ such as genetics (myopic parents tend to have myopic children more often than non-myopic parents), outdoor activities (time spent outdoors appears to be protective against the onset of myopia $\left.{ }^{3-6}\right)$, light-induced changes in retinal dopamine levels in animal models, ${ }^{7}$ and concentration of vitamin $\mathrm{D}$ in the blood. ${ }^{8}$ The association between myopia onset and near work remains elusive with some studies reporting relationship and others without relationship. ${ }^{6}$

Currently, the role of peripheral refraction in myopia onset has been highlighted, proposing that myopic eyes show a relative peripheral hyperopia (RPH) compared with hyperopic and emmetropic eyes, ${ }^{2,9-16}$ suggesting that RPH predicts myopia onset and progression. An eye shows RPH refraction when the peripheral images are focused behind the retinal surface assuming that the foveal image falls exactly on the retina (as in emmetropic, accommodating, or corrected eyes). ${ }^{17}$

However, little evidence supports that RPH predicts the development of myopia in humans. ${ }^{17-19}$ These reports mainly involve Chinese children population without little research in Caucasian population. ${ }^{20}$ So, the purpose of this study was to determine the peripheral refraction characteristics in young Caucasian (Mediterranean) children, over an 18-month monitoring period assessing the role of RPH refraction in myopia onset.

\section{Patients and methods}

This prospective and noninterventional study included three visits: the baseline visit, 12 months, and 18 months of follow-up.

\section{Study population}

This study involved a cohort of school children in Monopoli (Italy) in order to observe the differences in peripheral refraction related to non-myopic and myopice yes with special interest in myopia onset eyes. Eight-year-old children were examined at baseline and follow-up along 18 months.

Children with any refractive error were included and those with ocular pathology (amblyopia, strabismus, previous eye surgery, etc) or problems to fixate the targets monocularly were excluded.

Before enrollment, and after explaining the details of the study, informed written consent was obtained from at least one parent or legal guardian, and all children provided their verbal assent before conducting any eye measurement. Parents of patients consented to their inclusion in the study. The study was approved by the Institutional Committee of the University of Salento (Italy), and followed the tenets of the Declaration of Helsinki.

\section{Measurements}

Non-cycloplegic central and peripheral refraction, across the central $\pm 30^{\circ}$ of horizontal visual field angle, were performed with an open-field autorefractor (Shin-Nippon NVision K5001) on the left eyes following manufacturer's instructions. This is an open-view autorefractor with a measurement range of -22.00 to +22.50 diopters (D) for sphere and 10.00 D for cylinder with two different components (a swinging arm and an optical system) to permit subject fixation.

Peripheral refraction measurements were made sequentially. Children were instructed to keep their heads stationary, with the chin and forehead resting firmly against the chin and forehead rests, and fixate the target at far vision (a 20/200 Snellen chart at $5 \mathrm{~m}$ ). The instrument was carefully aligned to the center of pupil, and peripheral measurements were made turning the autorefractor (placed over a rotating support), first in nasal fields at $10^{\circ}(10), 20^{\circ}(20)$, and $30^{\circ}$ (30) and then in temporal fields at $10^{\circ}(-10), 20^{\circ}(-20)$, and $30^{\circ}(-30)$,guaranteeing that the patient maintain the fixation at the fixation chart. The right eye was occluded when the left-eye measurements were collected.

Biometric axial length (AL) measurement using partial coherence interferometry (IOL Master; Carl Zeiss Meditec AG, Jena, Germany) was collected in each study visit.

\section{Classification}

The eyes were classified according to their central refraction into two categories following the Atchison et a ${ }^{19}$ recommendations: "non-Myopia. Myopia" (nM. M), consisting of nM greater than-0.50 D (spherical equivalent) and $\mathrm{M}$ less than or equal to- $0.50 \mathrm{D}^{19}$

According to Atchison et al, ${ }^{19}$ a posterior subclassification in the three study groups was made on the basis of presence of myopia at baseline (Myopia initially: Mi), of absence of myopia at baseline (non-Myopia initially: $\mathrm{nMi}$ ), of presence of myopia after 18 months of follow-up (Myopia in final visit: Mf), and of absence of myopia after 18 months of follow-up (non-Myopia in final visit: nMf). So, children were divided into those who were non-myopic after 18 months (nMi-nMf), those who were non-myopic at baseline and developed myopia after 18 months (nMi-Mf), and those who remained myopic during the 18 months (Mi-Mf). 
If RPH refraction plays a significant role in myopia onset, differences in peripheral refraction between the three study groups will be present at baseline and after 18 months of follow-up, especially in eyes that developed myopia along the study (the nMi-Mf group).

\section{Statistical analysis}

The data were analyzed using the Statistical Package for the Social Sciences (SPSS for Windows software version 22.0; IBM Corporation, Armonk, NY, USA). Normal distribution of variables was assessed using the Kolmogorov-Smirnov test ( $P$-values $<0.05$ indicated that the data were not normally distributed). The results were presented as mean \pm standard deviation, and minimum and maximum value.

Relative peripheral refraction (RPR) was calculated by subtracting central refraction (spherical equivalent) from each peripheral refraction measurement. The univariate analysis of variance was conducted to assess the differences between study groups, analyzing the interactions of peripheral refraction or RPR. Peripheral refraction and RPR were plotted against the visual field angle for each study group ( $P$-values of $<0.05$ were considered statistically significant). Homogeneity of variances was assessed with Levene's test ( $P$-values of $<0.05$ were considered statistically significant).

\section{Results}

The study comprised 50 left eyes of 508 year old children ( $58 \%$ boys and $42 \%$ girls) with a mean spherical equivalent refraction of $+0.53 \pm 1.17 \mathrm{D}$ (range: -1.50 to $+5.63 \mathrm{D}$ ) (Table 1). According to the three study groups, $72 \%$ eyes were nMi-nMf, $10 \%$ were nMi-Mf, $8 \%$ were Mi-Mf, and $10 \%$ were in other groups (drop off $4 \%$ and $6 \%$ of eyes that "regressed" to less myopic or more hyperopic refraction at 18 months).

Peripheral refraction in all and subclassification study groups showed nonsignificant differences $\left(F_{36}=0.13 ; P=1.00\right)$ between groups and visits (Figure 1A).

Table 2 shows RPR in all and subclassification study groups. There were nonsignificant differences $\left(F_{36}=0.79\right.$; $P=0.80$ ) between groups and visits (Figure 1B).

Table I Central and peripheral refraction in all study visits and in each study group

\begin{tabular}{|c|c|c|c|c|}
\hline Group & $\begin{array}{l}\text { Field of peripheral } \\
\text { refraction }\end{array}$ & Baseline & 12 months & 18 months \\
\hline \multirow[t]{7}{*}{ All eyes } & -30 & $0.12 \pm 1.44(-2.25$ to 5.13$)$ & $0.4 \pm 1.27(-1.63$ to 5.63$)$ & $0.21 \pm 1.26(-1.5$ to 5.5$)$ \\
\hline & -20 & $0.11 \pm 1.26(-2.38$ to 5.13$)$ & $0.37 \pm 1.27(-2$ to 5.38$)$ & $0.20 \pm 1.27(-1.75$ to 5.25$)$ \\
\hline & -10 & $0.32 \pm 1.18(-1.25$ to 6$)$ & $0.4 \pm 1.25(-2.38$ to 5.63$)$ & $0.32 \pm 1.34(-2.63$ to 5.88$)$ \\
\hline & 0 & $0.53 \pm 1.17(-1.25$ to 5.63$)$ & $0.40 \pm 1.28(-2.75$ to 5.63$)$ & $0.4 \mathrm{I} \pm \mathrm{I} .38(-2.63$ to 6$)$ \\
\hline & 10 & $0.32 \pm 1.09(-1.5$ to 5.13$)$ & $0.42 \pm 1.28(-2.75$ to 6$)$ & $0.3 \mathrm{I} \pm 1.3 \mathrm{I}(-2.75$ to 6.13$)$ \\
\hline & 20 & $0.28 \pm 1.14(-1.63$ to 5.5$)$ & $0.31 \pm 1.36(-3.25$ to 6.25$)$ & $0.34 \pm 1.34(-3.5$ to 6.13$)$ \\
\hline & 30 & $0.19 \pm 1.21(-1.75$ to 5.63$)$ & $0.31 \pm 1.33(-3.00$ to 6.00$)$ & $0.27 \pm 1.36(-3.13$ to 6.38$)$ \\
\hline \multirow[t]{7}{*}{ nMi-nMf } & -30 & $0.43 \pm 1.38(-2.25$ to 5.13$)$ & $0.69 \pm 1.28(-1.00$ to 5.63$)$ & $0.53 \pm 1.26(-1.38$ to 5.5$)$ \\
\hline & -20 & $0.40 \pm 1.20(-1.13$ to 5.13$)$ & $0.66 \pm 1.26(-1.25$ to 5.38$)$ & $0.52 \pm 1.27(-1.25$ to 5.25$)$ \\
\hline & -10 & $0.54 \pm 1.23(-1.25$ to 6.00$)$ & $0.7 I \pm 1.20(-0.63$ to 5.63$)$ & $0.63 \pm 1.33(-0.75$ to 5.88$)$ \\
\hline & 0 & $0.84 \pm 1.15(-0.38$ to 5.63$)$ & $0.73 \pm 1.23(-0.63$ to 5.63$)$ & $0.76 \pm 1.30(-0.38$ to 6.00$)$ \\
\hline & 10 & $0.53 \pm 1.15(-0.88$ to 5.13$)$ & $0.69 \pm 1.26(-0.75$ to 6.00$)$ & $0.61 \pm 1.28(-0.63$ to 6.13$)$ \\
\hline & 20 & $0.53 \pm 1.17(-1.50$ to 5.50$)$ & $0.61 \pm 1.31$ ( -1.25 to 6.25$)$ & $0.65 \pm 1.30(-0.63$ to 6.13$)$ \\
\hline & 30 & $0.42 \pm 1.25(-1.25$ to 5.63$)$ & $0.64 \pm 1.28(-1.5$ to 6.00$)$ & $0.57 \pm 1.35(-0.75$ to 6.38$)$ \\
\hline \multirow[t]{7}{*}{ nMi-Mf } & -30 & $-0.33 \pm 2.08(-2.25$ to 1.88$)$ & $-0.79 \pm 0.76(-1.63$ to -0.13$)$ & $-0.54 \pm 0.31$ ( -0.88 to -0.25$)$ \\
\hline & -20 & $-0.13 \pm 1.42(-1.13$ to 1.5$)$ & $-0.17 \pm 0.95(-1$ to 0.88$)$ & $-0.75 \pm 0.66(-1.5$ to -0.25$)$ \\
\hline & -10 & $0.33 \pm 0.40(-0.13$ to 0.63$)$ & $-0.67 \pm 0.19(-0.88$ to -0.50$)$ & $-0.25 \pm 0.25$ ( -0.50 to 0.00$)$ \\
\hline & 0 & $0.21 \pm 0.14(0.13$ to 0.38$)$ & $-0.17 \pm 0.14(-0.25$ to 0.00$)$ & $-0.63 \pm 0.13(-0.75$ to -0.50$)$ \\
\hline & 10 & $-0.08 \pm 0.29(-0.25$ to 0.25$)$ & $-0.04 \pm 0.31$ ( -0.38 to 0.25$)$ & $-0.42 \pm 0.19(-0.63$ to -0.25$)$ \\
\hline & 20 & $-0.29 \pm 0.38(-0.63$ to 0.13$)$ & $-0.83 \pm 0.29(-1.00$ to -0.50$)$ & $-0.2 \mathrm{I} \pm 0.38(-0.63$ to 0.13$)$ \\
\hline & 30 & $-0.25 \pm 0.33(-0.63$ to 0.00$)$ & $-0.79 \pm 0.40(-1.25$ to -0.50$)$ & $-0.42 \pm 0.44(-0.88$ to 0.00$)$ \\
\hline \multirow[t]{7}{*}{ Mi-Mf } & -30 & $-0.79 \pm 0.89(-1.75$ to 0.63$)$ & $-0.58 \pm 0.75(-1.50$ to 0.25$)$ & $-1.10 \pm 0.43(-1.50$ to -0.38$)$ \\
\hline & -20 & $-0.83 \pm 0.75(-1.88$ to 0.25$)$ & $-1.02 \pm 0.70(-2.00$ to -0.25$)$ & $-1.10 \pm 0.52(-1.75$ to -0.38$)$ \\
\hline & -10 & $-0.67 \pm 0.37(-1.00$ to 0.00$)$ & $-0.90 \pm 0.91(-2.38$ to -0.13$)$ & $-1.19 \pm 0.79(-2.63$ to -0.38$)$ \\
\hline & 0 & $-0.79 \pm 0.30(-1.25$ to -0.50$)$ & $-1.17 \pm 0.84(-2.75$ to -0.50$)$ & $-1.27 \pm 0.75(-2.63$ to -0.50$)$ \\
\hline & 10 & $-0.52 \pm 0.53(-1.50$ to 0.00$)$ & $-0.94 \pm 0.95(-2.75$ to -0.25$)$ & $-1.08 \pm 1.02(-2.75$ to 0.13$)$ \\
\hline & 20 & $-0.7 I \pm 0.73(-1.63$ to 0.50$)$ & $-0.96 \pm 1.28(-3.25$ to 0.00$)$ & $-1.08 \pm 1.26(-3.5$ to 0.13$)$ \\
\hline & 30 & $-0.85 \pm 0.81$ ( $(-1.75$ to 0.25$)$ & $-0.90 \pm 1.18(-3.00$ to 0.38$)$ & $-1.06 \pm 1.13(-3.13$ to 0.00$)$ \\
\hline
\end{tabular}

Note: Data presented as mean \pm SD $(95 \% \mathrm{Cl})$.

Abbreviations: Mi-Mf, myopic during the 18 months; nMi-Mf, non-myopic at baseline and developed myopia after 18 months; nMi-nMf, non-myopic after 18 months. 


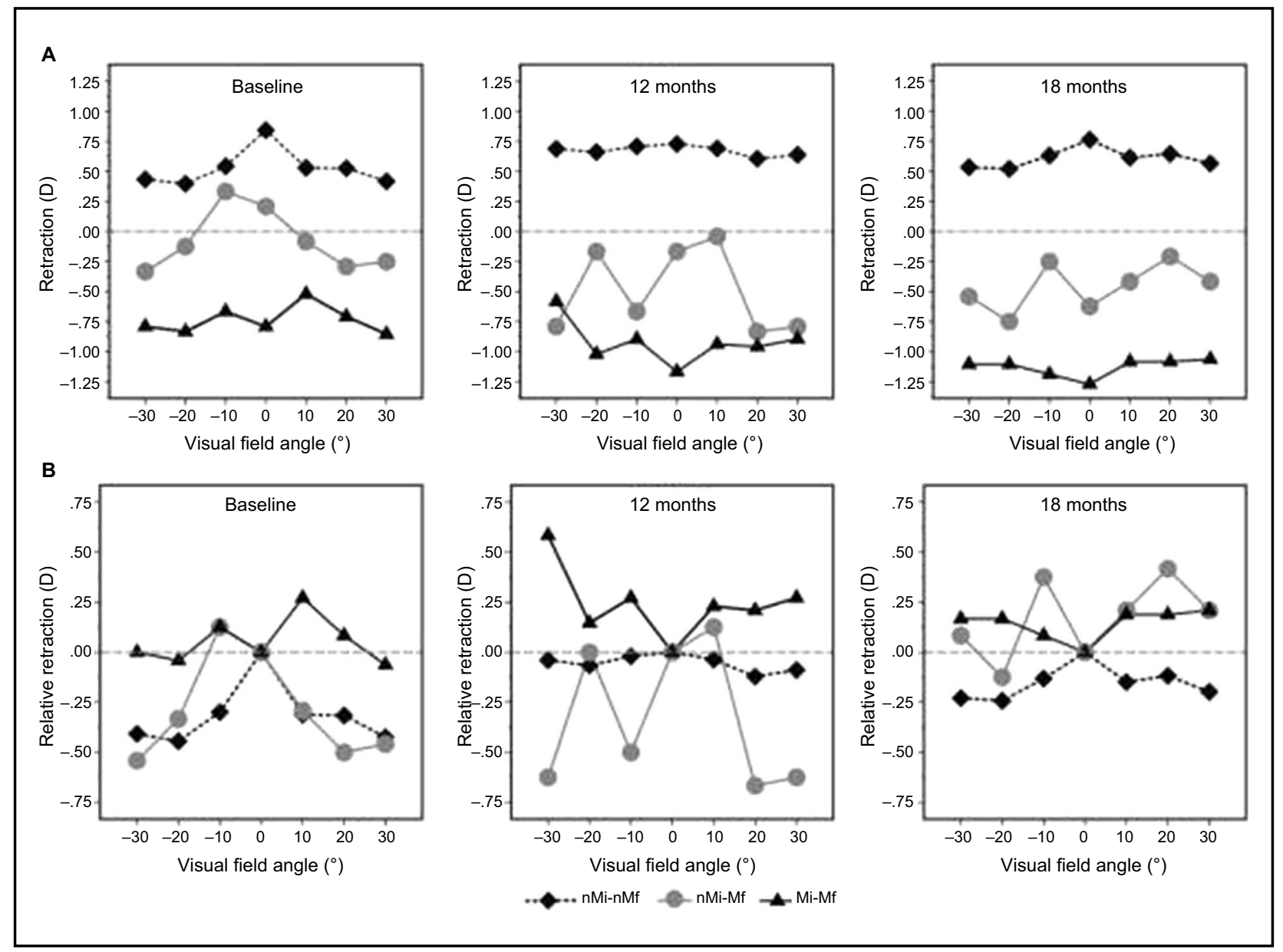

Figure I Peripheral refraction (A) and relative peripheral refraction (B) for the children in the "nonmyopia, myopia" classification at baseline (left), at I2 months (middle), and at 18 months (right).

Notes: Plotted after univariate analysis of variance. $(\mathbf{A})$ Central and peripheral refraction: statistically significant differences were found between groups $\left(F_{2}=73.2 \mathrm{I} ; \mathrm{P}<0.0 \mathrm{I}\right)$. However, there were nonsignificant differences between visits $\left(F_{2}=0.08 ; P=0.92\right)$ and visual field angle $\left(F_{6}=0.47 ; P=0.83\right)$ in refraction. $(B)$ RPR: statistically significant differences were found between groups $\left(F_{2}=13.61 ; P<0.01\right)$, visits $\left(F_{2}=3.92 ; P=0.02\right)$, and visual field angle $\left(F_{6}=2.86 ; P=0.01\right)$. However, the interaction between visits and RPR was statistically nonsignificant between groups $\left(F_{36}=0.79 ; P=0.80\right)$.

Abbreviations: RPR, relative peripheral refraction; nMi-nMf, non-myopic after 18 months; nMi-Mf, non-myopic at baseline and developed myopia after I8 months; Mi-Mf, myopic during the 18 months.

AL was different in each group $\left(F_{2}=5.93 ; P<0.01\right)$ and increased along the study visits $\left(F_{2}=39.83 ; P<0.01\right)$; however, a nonsignificant interaction between groups and visits $\left(F_{6}=0.09 ; P=0.99\right)$ was found (Figure 2$)$.

\section{Discussion}

Some controversy exists about the role of the peripheral refraction in myopia development, because animal research supports that peripheral feedback guides emmetropization and eye growing process ${ }^{1}$ with differences in peripheral refraction between myopic (hyperopic RPR) and non-myopic eyes, ${ }^{2,9-16}$ suggesting that hyperopic RPR could play a significant role in myopia onset and its progression.

Figure 1B shows that the non-myopic group (nMi-nMf) has "myopic" peripheral refraction at baseline and after 12 and 18 months of follow-up (in all peripheral visual field angle locations). In opposition, the myopic group (Mi-Mf) shows a hyperopic RPR at $10^{\circ}$ temporally and $10^{\circ}$ and $20^{\circ}$ nasally at baseline, and in all peripheral visual field angle locations in 12- and 18-month visits. Moreover, myopia increased (central refraction) from $-0.79 \pm 0.30 \mathrm{D}$ at baseline to $-1.27 \pm 0.75 \mathrm{D}$ after 18 months of follow-up. These results are consistent with previously reported data, ${ }^{2,9-16}$ which show a hyperopic RPR in the moderately myopic group compared with the non-myopic eyes along the horizontal meridian.

However, the non-myopic eyes at baseline that developed myopia after 18 months of follow-up (nMi-Mf) showed myopic peripheral refraction in all peripheral visual field angle locations, except at $10^{\circ}$ temporally at baseline and after 12 months of follow-up. The RPR shifted to hyperopia (except at $20^{\circ}$ temporally) after 18 months of follow-up. These results suggest that the hyperopic RPR showed in myopic eyes should 
Table 2 Relative peripheral refraction in all study visits and in each study group

\begin{tabular}{|c|c|c|c|c|}
\hline Group & Field of peripheral refraction & Baseline & 12 months & 18 months \\
\hline \multirow[t]{6}{*}{ All eyes } & -30 & $-0.4 \mathrm{I} \pm 0.78(-2.63$ to $\mathrm{I} .5)$ & $-0.01 \pm 0.56(-1.63$ to 1.25$)$ & $-0.2 \pm 0.53(-1.5$ to 1.13$)$ \\
\hline & -20 & $-0.42 \pm 0.59(-1.88$ to 1.13$)$ & $-0.03 \pm 0.49(-1.88$ to 0.88$)$ & $-0.21 \pm 0.48(-1.38$ to 0.88$)$ \\
\hline & -10 & $-0.2 I \pm 0.42(-1.25$ to 0.5$)$ & $-0.0 \mathrm{I} \pm 0.5(-\mathrm{I} .25$ to 2$)$ & $-0.08 \pm 0.39(-1.5$ to 0.63$)$ \\
\hline & 10 & $-0.21 \pm 0.53(-1.25$ to 0.88$)$ & $0.02 \pm 0.45(-I$ to $I)$ & $-0.1 \pm 0.45(-1.38$ to $I .13)$ \\
\hline & 20 & $-0.25 \pm 0.55(-2$ to $I)$ & $-0.09 \pm 0.54(-1.13$ to 1.13$)$ & $-0.07 \pm 0.5(-1.5$ to 1.13$)$ \\
\hline & 30 & $-0.34 \pm 0.6(-2.13$ to 0.88$)$ & $-0.1 \pm 0.58(-1.63$ to 1.38$)$ & $-0.14 \pm 0.54(-1.63$ to 1$)$ \\
\hline \multirow[t]{6}{*}{ nMi-nMf } & -30 & $-0.4 I \pm 0.68(-2.63$ to 0.75$)$ & $-0.04 \pm 0.5 \mathrm{I}(-\mathrm{I} .63$ to I.I3) & $-0.23 \pm 0.52(-1.5$ to 0.63$)$ \\
\hline & -20 & $-0.44 \pm 0.5(-1.5$ to 0.63$)$ & $-0.07 \pm 0.49(-1.88$ to 0.63$)$ & $-0.24 \pm 0.46(-1.38$ to 0.75$)$ \\
\hline & -10 & $-0.3 \pm 0.4 \mathrm{I}(-\mathrm{I} .25$ to 0.38$)$ & $-0.02 \pm 0.5$ I ( $(-1.25$ to 2$)$ & $-0.13 \pm 0.4 \mid(-1.5$ to 0.63$)$ \\
\hline & 10 & $-0.3 \mid \pm 0.5 I(-\mid .25$ to 0.88$)$ & $-0.04 \pm 0.46(-I$ to $I)$ & $-0.15 \pm 0.43(-1.38$ to 0.75$)$ \\
\hline & 20 & $-0.32 \pm 0.54(-2$ to $I)$ & $-0.12 \pm 0.52(-1.13$ to 1.13$)$ & $-0.12 \pm 0.4 \mathrm{I}(-1.5$ to 0.5$)$ \\
\hline & 30 & $-0.42 \pm 0.59(-2.13$ to 0.88$)$ & $-0.09 \pm 0.57(-1.63$ to 1$)$ & $-0.2 \pm 0.49(-1.63$ to $I)$ \\
\hline \multirow[t]{6}{*}{ nMi-Mf } & -30 & $-0.54 \pm 1.95(-2.38$ to 1.5$)$ & $-0.63 \pm 0.75(-1.38$ to 0.13$)$ & $0.08 \pm 0.19(-0.13$ to 0.25$)$ \\
\hline & -20 & $-0.33 \pm 1.28(-1.25$ to 1.13$)$ & $0 \pm 0.82(-0.75$ to 0.88$)$ & $-0.13 \pm 0.54(-0.75$ to 0.25$)$ \\
\hline & -10 & $0.13 \pm 0.38(-0.25$ to 0.5$)$ & $-0.5 \pm 0.22(-0.63$ to -0.25$)$ & $0.38 \pm 0.13(0.25$ to 0.5$)$ \\
\hline & 10 & $-0.29 \pm 0.38(-0.63$ to 0.13$)$ & $0.13 \pm 0.33(-0.13$ to 0.5$)$ & $0.21 \pm 0.26$ (0 to 0.5$)$ \\
\hline & 20 & $-0.5 \pm 0.5(-1$ to 0$)$ & $-0.67 \pm 0.38(-I$ to -0.25$)$ & $0.42 \pm 0.36(0$ to 0.63$)$ \\
\hline & 30 & $-0.46 \pm 0.47(-1$ to -0.13$)$ & $-0.63 \pm 0.54(-1.25$ to -0.25$)$ & $0.2 \mathrm{I} \pm 0.4(-0.25$ to 0.5$)$ \\
\hline \multirow[t]{6}{*}{ Mi-Mf } & -30 & $0 \pm 0.66(-0.75$ to 1.13$)$ & $0.58 \pm 0.52(-0.25$ to 1.25$)$ & $0.17 \pm 0.55(-0.5$ to 1.13$)$ \\
\hline & -20 & $-0.04 \pm 0.54(-0.88$ to 0.75$)$ & $0.15 \pm 0.46(-0.63$ to 0.75$)$ & $0.17 \pm 0.45(-0.5$ to 0.88$)$ \\
\hline & -10 & $0.13 \pm 0.38(-0.5$ to 0.5$)$ & $0.27 \pm 0.38(-0.25$ to 0.88$)$ & $0.08 \pm 0.19(-0.25$ to 0.25$)$ \\
\hline & 10 & $0.27 \pm 0.43(-0.5$ to 0.63$)$ & $0.23 \pm 0.32(0$ to 0.75$)$ & $0.19 \pm 0.57(-0.5$ to 1.13$)$ \\
\hline & 20 & $0.08 \pm 0.55(-0.63$ to $I)$ & $0.2 \mathrm{I} \pm 0.56(-0.5$ to $\mathrm{I})$ & $0.19 \pm 0.74(-0.88$ to 1.13$)$ \\
\hline & 30 & $-0.06 \pm 0.62(-0.75$ to 0.75$)$ & $0.27 \pm 0.57(-0.25$ to 1.38$)$ & $0.2 \mathrm{I} \pm 0.68(-0.75$ to $\mathrm{I})$ \\
\hline
\end{tabular}

Note: Data presented as mean \pm SD $(95 \% \mathrm{Cl})$.

Abbreviations: Mi-Mf, myopic during the 18 months; nMi-Mf, non-myopic at baseline and developed myopia after 18 months; nMi-nMf, non-myopic after 18 months.

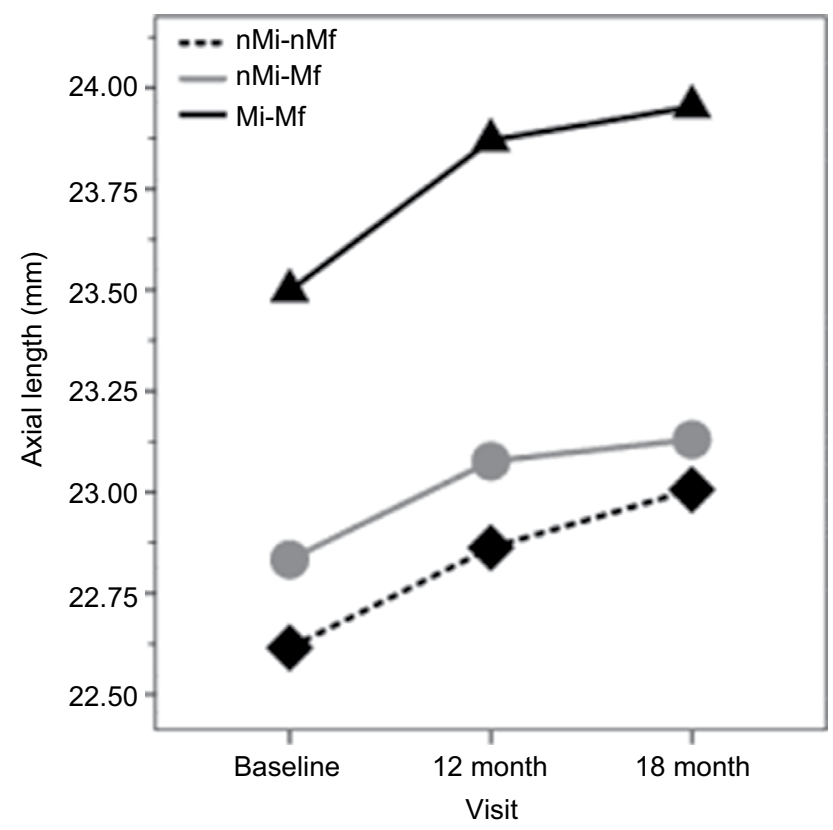

Figure 2 Axial length in all study visits and in each study group. Abbreviations: $n M i-n M f$, non-myopic after 18 months; nMi-Mf, non-myopic at baseline and developed myopia after 18 months; Mi-Mf, myopic during the 18 months.

be a consequence of myopia development and not a trigger factor or developing factor for myopia onset. ${ }^{17-19}$

The findings of this study are in line with the previous reports. Sng et al ${ }^{18}$ studied 187 Chinese children (Singapore) with ages between 3.4 and 15.8 years along 12 months. Their results suggested that RPH was not an important factor in myopia development, without preceding the onset of myopia, as found in the baseline visit. Lee and $\mathrm{Cho}^{17}$ concluded that baseline RPR could not predict changes in central refraction over time after study refraction changed in 58 Chinese children of 6-9 years old, during 12 months of follow-up. Atchison et $\mathrm{al}^{19}$ reported a large longitudinal study with two big sample size groups of Chinese children (2,893 of 7 years old and 2,267 of 14 years old) that found that hyperopic RPR did not predict the development or progression of myopia in Chinese children.

Mutti et $\mathrm{al}^{20}$ studied the role of RPH as a risk factor in myopia onset and its progression in a large sample of 774 myopic children (8.8 years old) of various ethnic backgrounds (Whites and Native Americans, Asians, and Hispanics) along 1-year progression interval and concluded that hyperopic RPR appeared to exert little influence on myopia onset and progression, or on eye axial elongation as found in the results of this study (Figure 2). Mutti et $\mathrm{al}^{20}$ found a significant interaction between RPR and ethnicity proposing that each diopter of hyperopic RPR conferred a greater risk of myopia onset in Asian children, a lower risk in African-American children, and no significant increase in Hispanic, Native 
American, or white children, which is in accordance with the results of this study that suggest no effect of hyperopic RPR in the Caucasian (Mediterranean) children population (Figure 1). The role of ethnicity in myopia onset and progression was clearly established with epidemiologic research that suggested high prevalence and risk in Asian population. ${ }^{21-24}$ However, to the best of our knowledge, this is the first report of the RPR effect on myopia development in Caucasian (Mediterranean) children population.

The findings of this study and the previous results ${ }^{17-19}$ suggest that treatment focused on modifying the retinal peripheral image to reduce the rate of myopia progression will be related with other factors different from peripheral refraction (PR) value, and other factors like ethnicity, ${ }^{20}$ genetics, outdoor activities, and light exposure ${ }^{2-8}$ may be taken into consideration.

However, different interventions have been proposed to reduce myopia with different efficacy results. ${ }^{25,26}$ Most common interventional actions could be summarized in undercorrection of myopic refractive error (without any effect to slow myopia progression, even a slight increase in its progression), ${ }^{25}$ gas-permeable contact lenses (without any effect to slow myopia progression in children), ${ }^{25,26}$ bifocal or multifocal spectacles (providing a small slowing effect in myopia progression with some myopia control in children with high accommodative lag and near-point esophoria), ${ }^{25,27,28}$ orthokeratology (with a significant effect to slow eye growth), ${ }^{25,29}$ soft bifocal contact lenses (slowing myopia progression between $25 \%$ and $46 \%$ ), ${ }^{25,30}$ and antimuscarinic agents (slowing myopia progression between 51\% and $77 \%) \cdot{ }^{25,26,31,32}$ So, the role of peripheral retina image in the development of central refraction is not irrelevant ${ }^{19}$ and more research is necessary to clarify the actual reasons for the efficacy of these treatments in myopia control.

There are some concerns and limitations about this research. The sample size is small, similar to previous reports. ${ }^{9,11,12,15-17}$ It has a less number of eyes that develop myopia, but this is an expected result according to myopia prevalence..$^{25,26}$ Myopia onset is found in $10 \%$ of the studied eyes, which is in accordance with the Mutti results that showed myopia onset in $16 \%$ of a large sample $(n=2,043)$ of children. ${ }^{20}$ Moreover, $\mathrm{AL}$ is increasing even without any change in RPR, which could be related with physiologic eye growth in children under 6 years, which could not mean myopia onset or development and may be related with normal emmetropization process. To reduce these limitations, multicenter studies are necessary to guarantee a large study sample. Other limitation is the range of ametropia explored because, to assess myopia onset, low hyperopic and emmetropic eyes should be included and followed up in time. For this reason, the refraction range included in this study is small; however, a previous classification ${ }^{19}$ was followed, making the results easily comparable with previous reports. The inclusion of other factors like genetics (number of parents with myopia), hours spent outside, or hours of light requires an increasing sample size. Multicenter, well-controlled trials are necessary to provide evidence-based results. Another difference with previous reports is related with the use of cycloplegia, but our results shows similar trend than previous reports that use cycloplegia. ${ }^{17-19}$ Finally, the role of vertical field should be elucidated, because this study was limited to the horizontal field, as most previous research., ${ }^{2,-16}$

\section{Conclusion}

The results are in line with the previous reports ${ }^{10,15,18,19}$ of peripheral refraction along the horizontal visual field that described an hyperopic relative peripheral shift change in myopic eyes and differences in RPR between myopic or hyperopic and emmetropic eyes. However, the results suggest that RPR cannot predict the development or progression of myopia in Caucasian (Mediterranean) children and that the efficacy in slowing myopia progression obtained with treatments that manipulate the peripheral refraction should be related with other factors different from peripheral refraction.

\section{Acknowledgments}

The authors thank Elena Rubino for his assistance in providing the IOL Master instrument. This research received no specific grant from any funding agency in the public, commercial, or not-for-profit sectors.

\section{Disclosure}

The authors report no conflicts of interest in this work.

\section{References}

1. Smith EL III. Prentice award lecture 2010: A case for peripheral optical treatment strategies for myopia. Optom Vis Sci. 2011; 88: 1029-1044.

2. Mutti DO. Hereditary and environmental contributions to emmetropization and myopia. Optom Vis Sci. 2010;87:255-259.

3. Jones LA, Sinnott LT, Mutti DO, Mitchell GL. Moeschberger ML. Zadnik K. Parental history of myopia. sports and outdoor activities. and future myopia. Invest Ophthalmol Vis Sci. 2007;48:3524-3532.

4. Rose KA, Morgan IG, Ip J, et al. Outdoor activity reduces the prevalence of myopia in children. Ophthalmology. 2008;115:1279-1285.

5. Wu PC, Tsai CL, Wu HL, Yang YH, Kuo HK. Outdoor activity during class recess reduces myopia onset and progression in school children. Ophthalmology. 2013;120:1080-1085.

6. Ramamurthy D, Lin Chua SY, Saw SM. A review of environmental risk factors for myopia during early life. childhood and adolescence. Clin Exp Optom. 2015;98:497-506.

7. Lan W, Yang Z, Feldkaemper M, Schaeffel F. Changes in dopamine and ZENK during suppression of myopia in chicks by intense illuminance. Exp Eye Res. 2016 Apr;145:118-124. 
8. Tideman JW, Polling JR, Voortman T, et al. Low serum vitamin D is associated with axial length and risk of myopia in young children. Eur J Epidemiol. 2016;31:491-499

9. Millodot M. Effect of ametropia on peripheral refraction. Am J Optom Physiol Opt . 1981; 58: 691-695.

10. Mutti DO, Sholtz RI, Friedman NE, Zadnik K. Peripheral refraction and ocular shape in children. Invest Ophthalmol Vis Sci. 2000;41:1022-1030.

11. Logan NS, Gilmartin B, Wildsoet CF, Dunne MC. Posterior retinal contour in adult human anisomyopia. Invest Ophthalmol Vis Sci. 2004;45: 2152-2162.

12. Atchison DA, Pritchard N, Schmid KL, Scott DH. Jones CE. Pope JM. Shape of the retinal surface in emmetropia and myopia. Invest Ophthalmol Vis Sci. 2005;46:2698-2707.

13. Atchison DA, Pritchard N, Schmid KL. Peripheral refraction along the horizontal and vertical visual fields in myopia. Vision Res. 2006;46: $1450-1458$.

14. Mutti DO, Hayes JR, Mitchell GL, et al. Refractive error, axial length, and relative peripheral refractive error before and after the onset of myopia. Invest Ophthalmol Vis Sci. 2007;48:2510-2519.

15. Chen X, Sankaridurg P, Donovan L etal. Characteristics of peripheral refractive errors of myopic and non-myopic Chinese eyes. Vision Res 2010; 50: 31-35.

16. Ehsaei A, Mallen EA, Chisholm CM, Pacey IE. Cross-sectional sample of peripheral refraction in four meridians in myopes and emmetropes. Invest Ophthalmol Vis Sci 2011; 52: 7574-7585.

17. Lee TT, Cho P. Relative peripheral refraction in children: twelve-month changes in eyes with different ametropias. Ophthalmic Physiol Opt. 2013;33:283-293.

18. Sng CC, Lin XY, Gazzard G, et al. Change in peripheral refraction over time in Singapore Chinese children. Invest Ophthalmol Vis Sci. 2011;52:7880-7887.

19. Atchison DA, Li SM, Li H, et al. Relative peripheral hyperopia does not predict development and progression of myopia in children. Invest. Ophthalmol. Vis. Sci. 2015;56:6162-6170.

20. Mutti DO, Sinnott LT, Mitchell GL, et al. Relative peripheral refractive error and the risk of onset and progression of myopia in children . Invest Ophthalmol Vis Sci. 2011; 52: 199-205.
21. Pan CW, Zheng YF, Anuar AR et al. Prevalence of refractive errors in a multiethnic Asian population: the Singapore epidemiology of eye disease study. Invest Ophthalmol Vis Sci. 2013; 54: 2590-2598.

22. Saw SM, Chan YH, Wong WL et al. Prevalence and risk factors for refractive errors in the Singapore Malay Eye Survey. Ophthalmology. 2008; 115: 1713-1719.

23. Kim EC, Morgan IG, Kakizaki H, Kang S, Jee D. Prevalence and risk factors for refractive errors: Korean National Health and Nutrition Examination Survey 2008-2011. PLoS One. 2013; 8: e80361.

24. L Guo, J Yang, J Mai, et al. Prevalence and associated factors of myopia among primary and middle school-aged students: a school-based study in Guangzhou. Eye (Lond). 2016;30:796-804.

25. Walline JJ. Myopia Control: A Review. Eye Contact Lens. 2016;42: 3-8.

26. Walline JJ, Lindsley K, Vedula SS, Cotter SA, Mutti DO, Twelker JD. Interventions to slow progression of myopia in children. The Cochrane database of systematic reviews. 2011;12:CD004916.

27. Edwards MH, Li RW, Lam CS, et al. The Hong Kong progressive lens myopia control study: study design and main findings. Invest Ophthalmol Vis Sci. 2002;43:2852-2858.

28. Aller TA. Clinical management of progressive myopia. Eye. 2014;28:147-153.

29. Sun Y, Xu F, Zhang T, et al. Orthokeratology to Control Myopia Progression: A Meta-Analysis. PLoS ONE. 2015;10:e0124535.

30. Sankaridurg P, Holden B, Smith E 3rd, et al. Decrease in Rate of Myopia Progression with a Contact Lens Designed to Reduce Relative Peripheral Hyperopia: One-Year Results. Invest Ophthalmol Vis Sci. 2011;52:9362-7.

31. Siatkowski R, Cotter S, Miller JM, et al. Safety and Efficacy of $2 \%$ Pirenzepine Ophthalmic Gel in Children With Myopia: A 1-Year, Multicenter, Double-Masked, Placebo-Controlled Parallel Study. Arch Ophthalmol. 2004;122:1667-1674.

32. Chia A, Chua WH, Cheung YB, et al. Atropine for the treatment of childhood myopia: safety and efficacy of $0.5 \%, 0.1 \%$, and $0.01 \%$ doses (Atropine for the Treatment of Myopia 2). Ophthalmology. 2012;119:347-54

\section{Clinical Optometry}

\section{Publish your work in this journal}

Clinical Optometry is an international, peer-reviewed, open access journa publishing original research, basic science, clinical and epidemiological studies, reviews and evaluations on clinical optometry. All aspects of patient care are addressed within the journal as well as the practice of optometry including economic and business analyses. Basic and clinical
Dovepress

research papers are published that cover all aspects of optics, refraction and its application to the theory and practice of optometry. The manuscript management system is completely online and includes a very quick and fair peer-review system, which is all easy to use. Visit http://www.dovepress. com/testimonials.php to read real quotes from published authors. 